\title{
OTTO MARIA CARPEAUX: O QUE NÃO PÔDE SER DITO
}

\section{OTTO MARIA CARPEAUX: WHAT COULD NOT HAVE BEEN SAID}

\author{
Carol Colffield*
}

\section{Resumo}

Reconstituir vidas na forma escrita é também navegar sobre os silêncios de seus protagonistas. Neste ensaio, que é parte de um universo de estudo maior focado nos intelectuais judeus perseguidos pelo nazifascismo e refugiados no Brasil, enveredamos pelos silêncios de um desses personagens, Otto Maria Carpeaux (Viena, 1908 - Rio de Janeiro, 1978) e pelas descobertas que resultaram da análise de documentos obtidos em arquivos na Áustria e em Israel, os quais revelam aspectos até então não registrados pela historiografia no que se refere tanto às origens do autor quanto ao seu passado de perseguições na Europa. Além do interesse intrínseco à própria trajetória de Carpeaux, tais descobertas confirmam que, em seu caso, o exílio não significou o fim da violência.

Palavras-chave: Otto Maria Carpeaux, Otto Maria Karpfen, Carpeaux, Intelectuais Judeus, Refugiados Judeus.

\begin{abstract}
To reconstitute lives in written form is also to navigate the silences of the protagonists. In this essay, which is part of a larger universe of study focused on Jewish intellectuals who were persecuted by Nazism and took refuge in Brazil, we turn to the silence of one of those

\footnotetext{
* Doutoranda do Programa de Pós-Graduação em Estudos Judaicos e Árabes (FFLCH-USP). Pesquisadora do Arqshoah-LEER-USP e bolsista do Projeto Vozes do Holocausto, ambos coordenados pela Profa. Dra. Maria Luiza Tucci Carneiro.
} 
Cad. Líng. Lit. Hebr., n. 15, p. 145-154, 2017

characters, Otto Maria Carpeaux (Viena, 1908 - Rio de Janeiro, 1978), and to the discoveries that resulted from the analysis of documents obtained from archives in Austria and Israel, which reveal aspects not recorded by the historiography with regard both to the author's origins and to his past of persecutions in Europe. In addition to the interest to Carpeaux's own trajectory, such findings confirm that, in his case, the exile did not mean the end of violence. Keywords: Otto Maria Carpeaux, Otto Maria Karpfen, Carpeaux, Jewish Intellectuals, Jewish Refugees. 
ColfFIELD, Carol. Otto Maria Carpeaux: O Que Não Pôde Ser Dito

Otto Maria Carpeaux foi um intelectual ao mesmo tempo brilhante e polêmico que, durante as quatro décadas em que viveu no Brasil, onde chegou em 1939 como refugiado do nazismo, deixou profundas marcas na vida intelectual do país. Nos últimos anos, sua obra tem despertado renovado interesse, materializado na republicação de vários de seus artigos e livros, incluindo sua monumental História da Literatura Ocidental em 10 volumes, publicados pela editora Leya em 2014. Mas apesar dos admiradores, das polêmicas e dos inúmeros escritos sobre Carpeaux, pouco se conhece sobre as raízes deste intelectual que chegou ao país na condição de "católico não ariano", singular rótulo atribuído pelo governo brasileiro a um grupo de homens e mulheres de origem judaica que, mediante o apelo do Papa Pio XII ao governo Vargas, receberam vistos de entrada no Brasil sob a condição de que se convertessem ao catolicismo ${ }^{1}$.

Em meio ao pouco que se conhece sobre as três primeiras décadas da vida de Otto Maria Karpfen - seu verdadeiro nome antes da chegada ao Brasil - está o fato de que, diferentemente da maioria dos demais portadores dos mencionados vistos, sua conversão ao catolicismo não foi forçada. Junto com sua esposa, Helene [Silberherz] Karpfen - proveniente de uma família judaica da Galícia -, Carpeaux havia abraçado sua nova religião já no início dos anos 1930, em Viena, tendo-se dedicado profissionalmente a escrever para diversos periódicos cristãos como o Der Christliche Ständestaat. Ao mesmo tempo, participou ativamente de grupos de resistência intelectual ao nazismo liderados por teólogos católicos como Johannes Oesterreicher e Dietrich von Hildebrand ${ }^{2}$. Sobre a maior parte de seu passado

\footnotetext{
${ }^{1}$ Esse fenômeno foi analisado pela primeira vez na historiografia brasileira por Maria Luiza Tucci Carneiro em seus livros $O$ anti-semitismo na Era Vargas: fantasmas de uma geração, 1930-1945 (3. ed. São Paulo: Perspectiva, 2001, p. 172-185) e Cidadão do mundo: o Brasil diante do Holocausto e dos judeus refugiados do nazifascismo (São Paulo: Perspectiva, 2010, pp. 165-179). Sobre este tema ver também: MILGRAM, Avraham. Os Judeus do Vaticano: A Tentativa de Salvação de Católicos Não Arianos da Alemanha ao Brasil Através do Vaticano (1930-1942). Rio de Janeiro: Imago, 1994. Esta obra traz uma lista completa dos católicos não-arianos salvos pela missão diplomática sediada no Vaticano.

2 Os grupos formados no início da década de 1930, em Viena, em torno das figuras de Johannes Oesterreicher (1904-1993) e Dietrich von Hildebrand (1889-1977) - o primeiro de família judaica, o segundo de família
} 
Cad. Líng. Lit. Hebr., n. 15, p. 145-154, 2017

na Europa, no entanto, o próprio Carpeaux encarregou-se de lançar um espesso manto de silêncio.

A busca por iluminar alguns espaços debaixo dos muitos mantos nas histórias desses refugiados é o que move meu trabalho, voltado a trilhar não somente pelas ideias que esses homens e mulheres legaram através de suas inúmeras realizações, mas também por suas trajetórias antes, durante e depois da ruptura imposta pelo nazismo; o resultado, em resumo, são escritos de vida. Contudo, emprestando a afirmação de James Boswell (1953, P. 22), precursor e mestre do gênero, meu propósito ao registrar essas vidas não é apresentar panegíricos. No caso do grupo humano sobre o qual meu estudo está focado, ao interesse intrínseco em relação à sua produção soma-se o aspecto de terem sido protagonistas de primeira hora - duplamente perseguidos, como intelectuais e como judeus - de um período tragicamente ímpar na história da humanidade; como tal, as questões que a análise de suas ações e reações suscitam são inúmeras.

Mas, além dos espaços pouco iluminados nos quais é preciso operar, há muitas vezes elementos que a própria historiografia de certa forma calcifica, lançando mais e mais camadas de tecido aos referidos mantos. Em alguns casos, certas particularidades, quando tomadas de forma equivocada como se fossem fatos, desviam o processo de pesquisa na direção de verdadeiras ruas sem saída; outras vezes impedem vislumbrar ou compreender o porquê de certos comportamentos ou atitudes. No caso da reconstituição de histórias de vida transcorridas durante os anos de totalitarismo nazista ou fascista - embora isso também seja válido para outros momentos históricos e outros regimes - muitas dessas particularidades são fundamentais não somente para entender a trajetória recontada, mas também para entender ou reafirmar o entendimento do próprio modo como esses sistemas operavam.

protestante, ambos convertidos ao catolicismo - sentariam as bases para o que em 1965, inaugurou uma nova era nas relações judaico-cristãs, traduzida no seminal documento Nostra Aetate, do qual Oesterreicher foi um dos relatores. (CONNELLY, 2007, 2012). 
ColfFIELD, Carol. Otto Maria Carpeaux: O Que Não Pôde Ser Dito

Ao percorrer a história de Otto Maria Carpeaux, a busca empreendida conduziu-me por caminhos que em parte contradiziam um ponto fundamental presente em escritos sobre o jornalista no que diz respeito às suas origens. Um desses aspectos, reiterado em artigos, análises e citações biográficas, refere-se ao suposto fato de que era filho de pai judeu e mãe católica. Documentos obtidos no desenrolar da pesquisa, no entanto, não somente refutam essa afirmação - ambos pais eram, na verdade, judeus - como também revelam um desfecho trágico.

O ano desse desfecho foi 1942, inaugurado no calendário nazista com a notória reunião mantida em 20 de janeiro por um grupo de oficiais do Reich em uma residência à beira do lago Wannsee. O propósito dessa reunião era discutir e coordenar a "Solução final do problema judaico"; traduzindo: debater formas "eficazes" de aniquilar a totalidade do povo judeu - muito embora o extermínio já viesse ocorrendo a cargo de esquadrões móveis de fuzilamento após a invasão da União Soviética em junho de 1941. As minutas de Wannsee revelam que, além das deliberações que giraram em torno dos "melhores" métodos de extermínio, os representantes das várias agências do Reich ali reunidas, rediscutiram ad nauseam definições a respeito de quem devia ser ou não considerado judeu em conformidade com os termos raciais decretados em 1935 com as Leis de Nuremberg.

Nesse mesmo ano de 1942, aqui no Brasil, enquanto os amigos de Carpeaux tentavam interceder junto ao governo de Getúlio Vargas para que fosse outorgada ao austríaco a cidadania brasileira com base na sua já grande contribuição à cultura nacional (KOIFMAN, 2015) as garras do nazismo encarregavam-se de destruir também todo e qualquer resquício das vidas daqueles que, perseguidos, haviam abandonado o continente. No caso de Carpeaux, no dia 28 de fevereiro daquele ano, a Universidade de Viena, então regida por autoridades impostas pelo governo central da Alemanha, destituía Otto Karpfen de seu título de doutor. 
Cad. Líng. Lit. Hebr., n. 15, p. 145-154, 2017

Devido à sua origem judaica, como consta dos registros nos arquivos da instituição, era considerado "indigno de um grau acadêmico de uma universidade alemã"3.

Em 12 abril de 1942, Carpeaux - obviamente sem saber nada a respeito da infame reunião de cúpula nazista nem ainda provavelmente sobre a retirada de seu título - publicava em artigo no Correio da Manhã do Rio de Janeiro, uma profunda análise sobre o racismo alemão que intitulou "A religião da raça". Nele, afirmava:

A erudição máxima e a "literatura" habilíssima mostram-se incapazes de explicar o segredo da teoria racista: durante séculos, era um capricho de esquisitões e de repente adquiriu a força duma nova religião, insensível aos argumentos dos sábios e aos risos dos folhetinistas.

Usando a inesgotável força intelectual que lhe era característica, Carpeaux conduz o leitor do artigo pelos caminhos de diversos pensadores, buscando demonstrar a evolução de ideias afins ao tema. Assim, inicia descrevendo o pensamento de Tácito na Antiguidade, passa por Gobineau, na França, visita o círculo de Bayreuth na Alemanha e finalmente chega ao ideólogo nazista Alfred Rosenberg. Após essa jornada, no entanto, Carpeaux pergunta: "qu'est-ce que cela prouve?" [o que isso prova?]. Sua resposta: "Nada, nessa explicação histórica, explica o acento religioso do neorracismo alemão, o fanatismo, a intolerância inquisitorial, o entusiasmo de cruzada" (CARPEAUX, 1942, P. 1).

No entanto, embora concordemos que os elementos que relacionou em seu artigo sejam intrinsecamente inexplicáveis, foram exatamente esse fanatismo, essa intolerância e esse entusiasmo de cruzada os que obrigaram o próprio Carpeaux a fugir de sua Viena natal em março de 1938, menos de uma semana após o Anschluss - a anexação da Áustria pela Alemanha. Também foi essa mesma cruzada empreendida por um séquito de burocratas e

3 Texto original: "eines akademischen Grades einer deutschen Hochschule unwürdig”. Disponível em Gedenbuch für die Opfer des Nationalsozialismus an der Universität Wien, 1938 [Memorial para as Vítimas do Nacional-socialismo na Universidade de Viena, 1938]. 
soldados que chegou ao apartamento da Aloisgasse em Viena, onde residia sua mãe, Gisela. Através da análise de documentos obtidos junto ao Dokumentationsarchiv des österreischen Widerstandes [Arquivo de Documentação da Resistência Austríaca], o Österreichisches Staatsarchiv [Arquivo Estatal Austríaco] - ambos em Viena - e o Memorial Yad Vashem em Jerusalém, Israel, é possível que tenhamos chegado ao que constituiu o cerne - ou, ao menos, um dos pontos fundamentais - do silêncio do autor austríaco.

Filha do casal Hermann e Natalie [Birnbaum] Schmelz, Gisela nasceu em Cracóvia, Polônia, no dia 24 de abril de 1880. Em 21 de maio de 1899, aos dezenove anos, casou-se em Viena com o advogado Max Karpfen, dez anos mais velho. No ano seguinte, em 29 de março de 1900, deu à luz Otto, seu único filho. O Max Karpfen, que viu de perto os horrores da Primeira Guerra, não chegou a presenciar a barbárie dos praticantes daquilo que seu filho, décadas mais tarde, chamaria "a religião da raça", uma vez que falecera em novembro de 1931. Mas para os milhares de judeus da Áustria que permaneceram no país após o Anschluss, começou um intenso período de perseguições que, entre outras medidas, incluiu a exigência de declaração ao Reich de todo o patrimônio que possuíssem ${ }^{4}$. No caso de Gisela Karpfen, documentos datados a partir de junho de 1938 atestam detalhadamente o trâmite; nos diversos formulários e relatos escritos de próprio punho constam listas de objetos pessoais, contas em bancos, a pensão do esposo, propriedades imobiliárias etc ${ }^{5}$. Os documentos também revelam que, tal como foi imposto pelo regime para os residentes judeus do Reich, seu nome passou a ser Gisela Sara Karpfen ${ }^{6}$.

\footnotetext{
${ }^{4}$ Um decreto de 27 de abril de 1938 obrigou todos os judeus austríacos cujos bens superassem os 7.500 RM (Reichsmark, moeda instituída pelo regime nazista após a anexação do país) a declararem todos seus bens até o fim de junho de 1938.

${ }^{5}$ Dentre os vários documentos oficiais assinados por Gisela Karpfen aos quais tivemos acesso, o primeiro data de 27 de junho de 1938 e intitula-se "Verzeichnis über das Vermögen von Juden" [Lista Patrimonial dos Judeus]. Em outro formulário, este de 14 de junho de 1939, consta uma lista de objetos que inclui, entre outros, pulseiras, anéis, brincos, facas de prata e xícaras.

6 Através de uma lei que já havia sido aplicada aos judeus alemães, todas as mulheres tiveram "Sara" acrescentado a seu nome; no caso dos homens, acrescentava-se "Israel". Essa alteração foi incluída em todas as
} 
Cad. Líng. Lit. Hebr., n. 15, p. 145-154, 2017

Mas o pior ainda estava por vir. Em abril de 1942, aos 62 anos de idade, Gisela foi convocada pelas autoridades nazistas a apresentar-se no prédio de uma escola judaica localizada na Kleine Sperlgasse, a alguns minutos de seu endereço, local que servia como "ponto de coleta", ou Sammellager. Ali, judeus de toda a cidade de Viena chegavam a esperar dias por um novo procedimento de registro. Foi ali também que nesse momento Gisela foi obrigada a entregar todos seus valores pessoais e a transferir seu patrimônio para o Reich.

Sua espera no Sammellager durou até o dia 27 de abril de 1942, quando ela e mais 997 judeus vienenses foram conduzidos à praça localizada em frente à Aspangbahnhof, onde estava o trem que os levaria "para o Leste" - um dos muitos eufemismos usados pelo Terceiro Reich. O destino desse transporte, aos quais os burocratas de Adolf Eichmann atribuíram o número 18, era a princípio a cidade de Izbica, na Polônia, como mostra o carimbo estampado na lista de deportação (“Abgangsliste des 18. Transportes”/DÖW). No entanto, o trem acabou sendo conduzido para a cidade - também polonesa - de Wlodawa, distrito de Lublin, distante a apenas $7 \mathrm{~km}$ do campo de extermínio de Sobibor.

Os trâmites para o "carregamento" do Transporte 18 se estenderam pelo dia inteiro. Somente às 19 h1 1 daquele 27 de abril, o trem que levava a mãe de Otto Maria Carpeaux partiu da estação. Após 52 horas de viagem - portanto já na noite do dia 29 - o grupo chegou à estação de Wlodawa, de onde foram conduzidos a pé em direção ao gueto da cidade, a $6 \mathrm{~km}$ de distância, escoltados pelos quinze homens armados da Schutzpolizei [Polícia de Proteção], que estiveram a cargo do transporte por todo o trajeto. O grupo de deportados, que em mais de um terço era composto por pessoas que, como Gisela, tinham mais de 60 anos de idade,

certidões de nascimento de judeus do Reich e revogada somente após o fim da guerra. Em alguns documentos de Gisela onde há referências a seu filho, lê-se o nome Otto Israel Karpfen. 
chegou ao local determinado às 6 h00 da manhã do dia 30 de abril ${ }^{7}$. A partir desse ponto, a documentação disponível não permite determinar ao certo o destino final de Gisela: se foi no campo de extermínio de Sobibor ou em Belzec - onde boa parte dos milhares de judeus do gueto de Wlodawa foram assassinados - ou, ainda, se foi durante uma das Aktions levadas a cabo pelos alemães e seus colaboradores na própria cidade. Sabe-se, no entanto, que dos 998 judeus do Transporte 18, somente três homens que haviam sido selecionados para trabalhos forçados sobreviveram.

Finda a guerra, a Israelitische Kultusgemeinde, instituição pertencente à comunidade judaica em Viena encarregada de localizar sobreviventes do Holocausto e familiares de vítimas, encaminhou uma carta a Otto Maria Carpeaux no Rio de Janeiro informando: “A Sra. Gisela Karpfen foi deportada no dia 27 de abril de 1942 para Izbica e de lá não retornou"8. Embora a documentação disponível não permita determinar o momento exato em que Otto Maria Carpeaux recebeu a carta que revelava o destino de sua mãe, é possível vislumbrar um dos porquês do profundo silêncio que, durante seus muitos anos de vida no Brasil, ele guardou sobre o passado daquele Otto Karpfen cujas raízes estavam em Viena, mas que foram definitivamente cortadas em terras polonesas. Talvez, para ele, valesse a máxima de Wittgenstein: "O que não pode ser dito, deve ser calado"?.

\footnotetext{
7 A descrição sobre a jornada do Transporte 18 é detalhada no documento "Erfahrungsbericht über durchgeführten Judentransport" [Relatório sobre a condução de transporte de judeus], referente ao território da Polônia, produzido pelo Chefe de Polícia de Viena, no dia 4 de maio de 1942.

${ }^{8}$ Informação extraída de carta escrita e enviada por Otto Maria Karpfen no dia 2 de abril de 1964 ao Sr. Günther Menacher, encarregado do "Fonds zur Abgeltung von Vermögensverlusten politisch Verfolgter" [Fundo para a compensação das perdas patrimoniais de perseguidos políticos], Österreichische Länderbank.

9 Texto original: “Wovon man nicht sprechen kann, darüber muss man schweigen”. WITTGENSTEIN, 1921, p. 114 (ed. 1960).
} 
Cad. Líng. Lit. Hebr., n. 15, p. 145-154, 2017

\section{Bibliografia}

BOSWELL, J. Life of Samuel Johnson. London: Oxford University Press, 1953.

CARNEIRO, M. L. T. Cidadão do mundo: o Brasil diante do Holocausto e dos judeus refugiados do Nazifascismo. São Paulo: Perspectiva, 2010.

CARPEAUX, O. M. A religião da raça. Correio da Manhã, Rio de Janeiro, p. 1 e 2, 24 abr. 1942. Biblioteca Nacional. Hemeroteca Digital. Disponível em: http://memoria.bn.br/DocReader/089842 05/11037. Acesso: 25 de julho de 2017.

CONNELLY, J. Catholic racism and its opponents. The Journal of Modern History, Chicago, v. 79, n. 4, p. 813-847, dez. 2007.

. From Enemy to Brother: The Revolution on Catholic Teaching on the Jews, 19331965. Cambridge, MA: Harvard University Press, 2012.

KOIFMAN, F. Cidadão carioca: a naturalização de Otto Maria Carpeaux. Intellèctus, Rio de Janeiro, v. 14, n. 2, p. 169-188, 2015.

MILGRAM, A. Os judeus do Vaticano: a tentativa de salvação de católicos não arianos da Alemanha ao Brasil através do Vaticano (1930-1942). Rio de Janeiro: Imago, 1994.

WITTGENSTEIN, L. Tractatus Logico-Philosophicus: Logisch-philosophische Abhandlung. Frankfurt: Surkampf Verlag, 1960. 